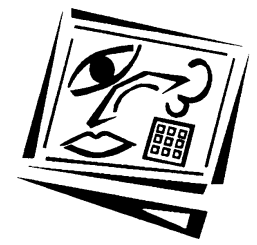

\title{
The interactive whiteboard: A transitional technology supporting diverse teaching practices
}

\author{
Arthur Winzenried, Barney Dalgarno and Jacqueline Tinkler \\ Charles Sturt University
}

\begin{abstract}
This article describes the findings of a qualitative study investigating teacher perspectives on the impact of interactive whiteboards (IWBs) on their classroom teaching practice, using intensive case studies focusing on six primary and secondary teachers from two rural schools. The study found that all teachers were enthusiastic, had seen improvements in student engagement, and were able to develop and evolve their IWB teaching strategies through explicit reflection. However, there was considerable diversity both in the ways in which the IWB was used and in the degree to which teachers changed their classroom teaching practices. Whereas some (Glover and Miller, 2001; Kennewell, 2006) have been critical of IWB adoption without clear pedagogical transformation or without utilisation of all IWB features, we argue that one of the IWB's key benefits is that it can be used initially without requiring a big shift in pedagogy but that it may gradually afford more major pedagogical changes over a longer period of time. These findings are important for the design of professional development in schools because with such a diversity of perceived IWB affordances, effective professional development is more likely to take the form of informal practice sharing than of specific hardware or software training.
\end{abstract}

\section{Introduction}

In the field of education at all levels there is much excitement, concern and angst regarding the involvement of technology in the learning process. Views can range from excitement at the idea of a 'connected classroom' to a fear of computerised tutors totally replacing the classroom teacher. Adding to some of the concerns is the sheer cost of technology, often seen as financially crippling as far as the school environment is concerned. Despite a number of researchers questioning the impact on schools of large scale investment in technology (e.g. Cuban, 2001; Somekh, 2004), few practitioners or researchers in the field would deny that there is value in the application of some technology to learning. More commonly, there is concern amongst those responsible for educational budgets as to the best allocation of scarce financial resources. One of the more promising recent developments has been the increasingly widespread availability of interactive whiteboards (IWBs), which, using a combination of a computer, a data projector and a large, touch-sensitive screen, provide an interface allowing tactile, widely observable and collaborative interaction. These pieces of equipment are being increasingly appreciated for their versatility and learning enhancement potential (Lee \& Winzenried, 2009).

\section{The literature}

There is a growing body of literature related to interactive whiteboards (IWBs) and their potential value in the teaching and learning process. Early literature tended to 
consist of case studies of implementation of IWBs in particular classrooms or schools, focussing either on the capabilities of the technology (Smith, 2003), on the perspective of teachers (Gatlin, 2004), the perspective of students (Hall \& Higgins, 2005) or combinations of all three (Glover \& Miller, 2001; Schuck \& Kearney, 2007). One of the largest early trials of IWB implementation in Australia was that undertaken at Richardson Primary School in the Australian Capital Territory (Kent 2004; Lee \& Boyle, 2003). The consensus from these various case studies was that IWBs were more readily adopted by teachers than many earlier technologies, that IWBs provided a range of technical capabilities of potential benefit in achieving positive learning outcomes across the full curriculum spectrum in contexts from early childhood to upper secondary, but that such benefits were very much dependant on the ways in which teachers used the IWBs in their own classrooms.

More broadly a number of researchers have attempted to explore the bigger picture question of whether information and communication technologies (ICTs) in general can improve learning and teaching (Higgins, 2003; Wishart \& Blease 1999), but the general consensus amongst researchers is that the more pertinent question is not whether ICTs can improve learning but how the potential learning benefits of particular technologies can be harnessed in particular learning contexts for achieving particular learning outcomes and what enabling and constraining factors exist that can help or hinder the learning process. Consistent with this more complex view of the role of technology in the learning process, more recent research on IWBs has focused on specific issues associated with IWB teaching and learning practice (Beauchamp, 2004; Glover, Miller, Averis \& Door, 2007; Lewin, Somekh \& Steadman, 2008) or has compared the affordances of IWBs with other learning technologies (Haldane, 2007; Lee \& Winzenried, 2009).

\section{Potential benefits of IWBs}

There are three key potential benefits of IWBs that are most frequently discussed in the literature: increases in student engagement, more effective visual representation, and learning through greater classroom interactivity. These are discussed in turn in the following paragraphs.

Beeland (2001) reports on a study showing an increase in student engagement as a result of the use of IWBs. Interestingly however, the applications of the IWB and the balance in its use by teachers and students had a direct effect on student engagement, though the same degree of effect was not necessarily consistent. Morgan (2008) studied the effect of IWBs on student engagement in junior high schools and also found beneficial effects of IWBs on student engagement in classroom lessons as well as improvements in student behaviour.

Various researchers have highlighted the capabilities of the IWB in displaying visual representations as being of major importance for learning, consistent with earlier studies exploring the value of visual representation more broadly for learning (McKendrick \& Bowden 1999; Smith \& Blankinship 2000). For example, Holmes (2009) highlights the value of visual representation of mathematics concepts using an IWB. In contrast, Reedy (2008) criticises the inappropriate use or overuse of PowerPoint presentations with IWBs and data projectors and the negative impact it can have on the degree to which learners actively engage in complex thinking and reasoning. Cutrim Schmid (2008) adds to this debate in identifying key benefits to the use of multimedia representations for language learning but also identifying potential 
problems with cognitive load and a lack of cognitive engagement if such representations are used inappropriately.

Chuang, Shen and Wang (2008) argue that the learning benefits of IWBs are very dependent on students interacting directly with the board themselves rather than, for example, observing the teacher doing so and that this interaction is particularly valuable when interactive responses are made public and discussed with the class. Across the literature, IWBs have been used interactively and it is on this score, that they appear in the literature to have performed particularly well (see, for example, McCormick, 2007). As pointed out by Cutrim Schmid (2008) for example, the actual type of interaction with the board is important and there is evidence (see, Zevenbergen \& Lerman, 2008, for example) that frequent low level interaction with the board may have a detrimental effect on the depth of cognitive engagement (see further discussion below).

\section{Teacher adoption of IWBs}

Armstrong, et al. (2005) consider classroom change with the introduction of IWBs and find that the role of the teacher is pivotal to these changes. Glover and Miller (2001) concur, identifying three types of teachers with differing attitudes towards the adoption of IWBs: missioners, tentatives and Luddites. In later work they concluded that in order to realise the potential benefits of an IWB, a number of conditions related to teacher attitudes had to be met: "(a) there was a will to develop and use the technology; (b) the teachers had to be willing to become mutually interdependent in the development of materials; and (c) there had to be some change of thinking about the way in which classroom activities were resourced" (Glover \& Miller, 2002, p.5). Beauchamp (2004) also emphasises the important role of the teacher in facilitating learning benefits from IWBs, and identifies five categories of teachers' use of the IWB: black/whiteboard substitute, apprentice user, initiate user, advanced user, and synergistic user. Shenton and Pagett (2007) agree that pedagogical change resulting from the implementation of IWBs is very much teacher dependant and identify diversity in IWB teaching approach as a key outcome of their own study.

A number of studies have found that IWBs are readily adopted by teachers and that their usage patterns continue to evolve over time. Bennett and Lockyer (2008) for example intensively studied four classroom teachers' use of an IWB over two school terms and concluded that all teachers found the technology easy to use and all were able to readily integrate the technology into their classroom teaching. Similarly Hedberg and Freebody (2007) in a study of 13 teachers' use of IWBs in conjunction with digital learning objects, found that "by the end of the year-long experience of innovation, almost all 13 participating teachers had moved to higher levels of use of the two innovatory technologies", (p.3). Gatlin (2004) suggests that initial teacher resistance is overcome after they experience positive changes in student participation and interest once the technology is introduced and advocates that IWBs be permanently installed in classrooms to give teachers a sense of ownership over the new technology.

\section{IWBs and pedagogical change}

In some contexts, IWBs have been promoted to teachers as requiring little or no change to existing lesson plans and this has been a perceived advantage (Gatlin, 2004). Kennewell (2006) also suggests that the use of an IWB generally does not require a 
fundamental change in the teacher's pedagogical paradigm, although he does not necessarily see this as a positive, because, he argues, the technology may be used in such a way as to reinforce rather than transform current teaching approaches. A number of authors have found that teachers' pedagogical approaches when using an IWB were consistent with the approaches they used when teaching without technology (Bennett \& Lockyer, 2008). Gray, Pilkington, Hagger-Vaughan and Tomkins (2007) argue that the idea of teachers transforming their pedagogy through the introduction of ICTs is much more complex than some have claimed and identify a number of reasons why teachers do not easily change their pedagogy.

Conversely, a number of researchers have noted that IWBs can have a profound impact on pedagogy. Haldane (2007) goes so far as to say that IWBs create a "distinctive pedagogy", drawing on Kozma's studies of how learning media define pedagogy. Mohon (2008) argues that pedagogical change through the use of an IWB can emerge but the new pedagogy will necessarily remain within the context of the existing philosophy of the teacher and will be limited by how much he or she wants to pursue new ideas in order to support learning, while Way et al.(2009) caution against generalisations about the impact of IWBs on teachers' pedagogy due to the enormous diversity of teaching approaches and the complex interplay of factors that contribute to an individual teacher's choice of strategy to meet particular student needs.

Wood and Ashfield (2007) found that, depending on the skill and experience of the teacher, use of an IWB could enhance the pace of whole class teaching sessions. Gatlin (2004) concurred, arguing that the increase in pace is due to the fact that teachers no longer have to spend time writing on or erasing from a whiteboard. Smith, Hardman and Higgins (2006) also found that classes where IWBs were used had a faster pace, but that there was an increase in whole class interaction and less group work. This is consistent with the findings of Zevenbergen and Lerman (2008) who found in a study exploring the use of IWBs in mathematics classrooms that lessons tended to be teacher directed and fostered shallow learning. It is possible that IWB strategies which involve frequent turn taking may result in surface level interaction and surface level cognitive engagement. This is consistent with the ideas of Cutrim Schmid (2008) who observed that, while IWBs improve the quantity of interaction, they do not necessarily have a qualitative impact.

For Hodge and Anderson (2007), however, although the introduction of IWBs led to an initial increase in teacher-centred approaches, this evolved over time towards approaches whereby students became more active participants in lessons. Sweeney (2010) also describes the way teachers in her study tended to initially use the IWB in a teacher-centred way with a focus on the use of the presentation capabilities of the whiteboard software before gradually evolving their pedagogy towards less scripted approaches.

\section{Professional development}

The effect of providing additional training for teachers was studied in depth by Miller and Glover (2007). They found that continuous professional development by a designated mentor, rather than general pedagogical and technological instruction, led to the most rapid progression from didactic to interactive teaching styles. Jewitt, Moss and Cardini (2007) identified pedagogical mentoring, rather than purely technical instruction for teachers, as being the key to IWBs acting as agents for change in pace 
and interactivity in the classroom, and Jones and Vincent (2006) reported similar findings in their study of the implementation of IWBs in a secondary school. This echoes Glover and Miller's earlier conclusions of 2001 that coaching, personal development and mutually reflective activities are essential to enhancing teacher usage of IWBs and the eventual classroom experience (see also Cutrim Schmid, 2007). Lewin, Scrimshaw, Somekh and Haldane (2009) studied the process used to facilitate the adoption of IWBs in a large number of primary schools in the UK and found that, unlike secondary schools, a 'cascade' approach to professional development was very successful and resulted in effective communities of practice developing within the schools.

Hammond et al. (2009), in a study exploring the factors leading to successful use of IWBs by student teachers found that access, support for, and modelling of, ICT use in the classroom were key issues and that the belief that ICT could make a positive difference to teaching and learning was also important. Shenton and Pagett (2007) found wide variance in the ways in which teachers use IWBs, suggesting that rather than the 'top down' commercial or professional models of transmission training, teachers need more of a 'bottom up' approach, which is more focussed on teachers' individual needs.

\section{This study}

Clearly, then, there are numerous examples of positive responses from teachers to the introduction of IWBs and clear evidence for increases in student engagement. What is still unclear is the ways in which teachers' IWB pedagogical strategies evolve over time, the degree to which fundamental pedagogical change occurs (or indeed is necessary or desirable), and the degree to which the evolution of strategies are predictable or specific to the individual. The exploration of these questions about the ways in which IWBs impact on teaching practice are important to policy makers in planning for support and training for teachers as part of wider IWB implementation strategies. This study addresses these questions by exploring in depth the effect on teaching practice of the provision of IWBs in the classrooms of two primary and four secondary teachers.

\section{Methodology}

In order to ascertain the nature of the impact of the installation of interactive whiteboards on teaching practice, a case study approach drawing on a phenomenological perspective was taken, using qualitative methods of data collection to explore the lived experience of teachers from their own perspectives. Stake (1995) describes three types of case study: intrinsic, instrumental, and collective. This study fits most closely to Stake's definition of a collective case study, where multiple cases are used in order to explore the characteristics of the wider population. Six teachers from two schools participated in the study, two primary teachers (teachers in a school for students aged 5 to 12), and four secondary teachers (teachers in a school for students aged 12 to 18). Both schools were located in or near a large regional centre in New South Wales (NSW) - the secondary school being in the town itself, the primary school being located in a small town with a population of around 4000 .

All participating teachers had an interactive whiteboard in their classrooms and the range of regular teaching experience with the IWB varied, from 1 to 8 months. Four of 
the interactive whiteboards were Electroboard Smartboards, with two in the secondary school being Panasonic boards (the key difference being that Panasonic boards necessitated the use of a special pen, whereas Smartboards could be used either with a purpose designed pen or with a finger). Both the secondary and the primary school purchased the IWBs from their own funds, and these were installed in the home rooms of the teachers who either expressed interest in having one, or were seen to be likely to use them. Use by other teachers was rare as a result of the boards being in the particular teachers' classrooms and room swapping would have been required for this to happen.

A series of semi structured interviews and lesson observations were conducted over the course of a six month period, and teachers were encouraged to use a reflective journal as a way of recording their thoughts and experiences of their IWB use over the course of the study as a prompt for subsequent interviews.

An initial interview conducted at the beginning of the study focused on the teachers' perceptions of the use of technologies for learning, their experiences with the use of technology in the classroom and their overall beliefs about teaching practice. This interview included questions about their perceptions of the way that their practice had already developed during the period that they have been using a whiteboard.

Each participant was interviewed five or six times and had their teaching observed three or four times as part of the project over a six month period. Except for the first and last interviews, interviews were conducted following the observation of a lesson by the interviewer. The interviews were semi-structured with broad questions developed in advance but with opportunities to ask clarifying and elaborating questions and to probe unexpected ideas emerging during the interviews. All interviews were audio recorded.

Classroom observations involved one researcher observing a class where the IWB was being used as a part of a lesson across a range of classes and teaching disciplines. These included secondary mathematics, science, social/environmental studies, and English, from years 8 to 12 (age range 13 to 18), as well as primary literacy, numeracy, science and technology, social/environmental studies and personal development. The interviews carried out after each lesson observation focused on the teachers' perceptions about their teaching practice during these lessons and during other recent lessons. The researcher observing the class also used their observation notes and the teachers' reflective journals as prompts for more in depth questioning of the teachers.

The final interview focused on the teachers' overall perceptions about the ways in which their practice had developed during the period of the study and the impact that the use of an interactive whiteboard had on their practice during this period. The results of these interviews were then transcribed and coded to identify commonalities across participant interviews. The coding was carried out as suggested by Miles and Huberman (1994), using an inductive or grounded coding approach using a sample of interviews, followed by a theoretically informed categorisation and code reduction process. These derived codes and categories were then used systematically in the coding of the full set of interviews during which some additional codes emerged and some minor adjustments were made to the categorisation scheme. 


\section{The participants' stories}

The following sections present a summary of the IWB teaching experience of each of the six participant teachers as evidenced by the data collected in this study. Names for the six teachers are pseudonyms to protect the teachers' anonymity.

\section{Sally}

Sally taught a year 6 (age range 10-12) class at a rural primary school with a population containing many students from disadvantaged socio-economic backgrounds. She had an IWB installed in her classroom at the beginning of the year in which the study occurred and had used it for one term at the commencement of the study. She had not previously used an IWB and had attended a single one day professional development activity organised by the education department (NSW Department of Education and Training). Sally was an enthusiastic adopter of the IWB and over the period of the study evolved her practice to the extent that by the end of the 6 month period she was using the IWB during almost all teaching sessions. She used it in a wide range of ways including as an enhanced whiteboard (for example using the ability to save and restore as a way of reviewing previous chalk and talk lessons), as a way of bringing contemporary content into the classroom to make learning more relevant to students (e.g. using YouTube, Google Maps and online news sites), as a way of explaining procedures (e.g. using a transparent overlay of a protractor), as a way of keeping students focused and involved in lessons (e.g. by having students take turns to enter their printed worksheet answers onto a copy of the worksheet on the IWB), and as a way of motivating and engaging students through whole class interactive tasks (using online mathematics activities and games).

As well as gradually introducing new IWB strategies aligned with the different curriculum areas within her teaching, becoming more skilled in the development of IWB resources, and becoming more confident and competent with the actual use of the board in front of the class, Sally also evolved her IWB pedagogical practice in a number of noticeable ways during the study. For example, she commented that she now focused less on the creation of polished colourful materials as she came to understand that it was the interactive aspects of the tasks she designed not the visual appeal that engaged the students. Another important aspect of her IWB practice which evolved during the study was her classroom management techniques and in particular her strategies for managing turn taking on the IWB. This was important because of the way in which anticipation of the students' turn on the IWB motivated students to behave appropriately and stay focused on their work. Overall Sally found that the IWB improved the motivation and engagement for a difficult to engage class, provided access to a wide range of new types of teaching resources, and most importantly resulted in noticeable improvements in academic achievement.

\section{Grace}

Grace has been a secondary teacher of English for the best part of forty years. Her school is located in a large regional centre and is attended by students from a wide socio-economic spectrum. While having seen many changes during those years she has not adopted technology in any considerable way. The introduction of IWBs to her learning area was an opportunity that she considered with just a little apprehension. 
While being highly knowledgeable in her subject area, her experiences with a Panasonic board over the last twelve months have led her to make some considerable changes to the style of her delivery. The study currently being considered began after Grace had less than six months experience with the board. It was not a technology that she used every class, tending to prefer a more 'stand and deliver' approach. With some limited experience using a school laptop, her major computer based use included the more common aspects of Microsoft Word and PowerPoint.

When first interviewed she was highly motivated about the potential of the technology, very willing to learn, but also very unsure of her own skills and of the board's potential. During the time that the research has taken, she has consistently tried new ideas, sought help from peers and the students themselves and consequently gained confidence with the technology. A number of new potential directions for her teaching of English have been realised with a considerable excitement being verbalised as regards new levels of engagement in her classes.

The board is used for many, but not all, of her classes; mainly for the purpose of focusing class discussions. PowerPoint presentations are often the basis of the board content, either generated by herself or by groups of students as they explore different literature and report back to the whole class. Participation is moderately active and general. No strict turn-taking is encouraged but considerable care is taken to ensure that everyone is involved regularly. Other than PowerPoint, no other software was observed in use.

\section{James}

James is a head teacher in the Human Society and its Environment (social/ environmental studies) Faculty at a large regional high school of 950 students and was observed teaching year 9-11 students (age range 14 to 17) in Business Studies and Geography. The school had recently acquired four interactive whiteboards one of which was allocated to the classroom in which James taught most of his lessons. James was enthusiastic about the potential of the board but also felt that he had not used it as much as he hoped he would have, especially its interactive capabilities, confessing he used it primarily to project videos and show visuals.

James had not used an interactive whiteboard before, but had seen them being used at a conference, and was excited by the possibilities he saw being demonstrated. He attended a number of professional development activities run by the NSW Department of Education and Training, but felt that he needed time to immerse himself in a project to really learn to use it well. He also felt that teachers at the school did not share their professional learning enough and that this had been a valuable way of learning in his previous school. He felt that he learnt a lot from his students and their use and exploration of the board, and that learning technology skills from students was more effective than learning from formal professional development sessions or other teachers.

James used the board primarily as a screen for visual material, which married with his previous teaching approach which involved extensive use of a data projector for similar purposes. His primary use of the board was to illustrate topics that were being presented with video and images from YouTube, Google and other web-based news sites, usually in a teacher centred way. In preparing lessons with the IWB, James found 
each time he prepared a new lesson he learnt something new to try, but felt he lacked the time to do a lot more in depth exploration.

James did comment that he had retained his teaching style - that of a story-teller - and had really used the IWB to enhance his existing teaching style. He still taught in a teacher-focused way, occasionally getting a few students to interact with the board for particular activities. Group work was not a part of his IWB use. James felt the board was engaging and that the use of technology was expected from students, although he was unsure of the learning benefits.

\section{Amanda}

Amanda has been teaching secondary science at her school for less than three years but in that time has been recognised for her experience by being appointed head of a large science faculty. She has been teaching for around ten years altogether. IWBs are not new to her although the year of the study marked the first full year in which she had access to the technology in her own classroom. This had enabled her to use the board as and when she wished. She indicated that she used it most lessons, although given that science has practical aspects as well, the board was not used for full lesson times. It tended to be most involved in the note taking aspects of the teaching, for simulations and for displaying Internet and other digital resources.

Finding digital resources for the IWB was a 'new' activity for Amanda and one she indicated that she very much enjoyed. She was not afraid to follow ideas presented in class and search for new resources with the class often leading them into an impromptu evaluation of web sites. Although she noted that considerable preparation time is taken up with searching for resources, overall she was convinced that there was less preparation time with the new technology and with the added advantage of being able to save outcomes for future lessons.

Classroom use of the board involved considerable teacher direction but students regularly carried out their own live searches, added notes to PowerPoint lesson note blanks and generally shared the operation of the board. No particular turn taking is involved though there was careful monitoring as to each student's involvement. One of the more common activities was access to an Internet site that included animated and interactive science movies. The students related extremely well to these and often arrived at the classroom (on time) and immediately asked to view content from this site: "can we have Tim and Moby?" (Brain POP, UK).

Amanda considered this as evidence that the technology is engaging the students and indicated that she felt highly motivated even in the face of classes that were causing concern to other teachers. In many other ways, she was convinced that her students were more motivated and that they learned and retained far more with the help of IWB technology. She indicated that they were more active in their learning and tended to take more control of their learning as a result.

\section{Sue}

Sue taught secondary mathematics at a large regional high school and was observed teaching two different maths classes - one a class of struggling students, and the other a mixed class of accelerated students including students from year 9 to year 11 (age range 14 to 17$)$. 
Sue's board was a Panasonic board which required the use of a pen, and this was seen as a negative factor and meant she had to watch the kids with the pens and keep them secure when not in use. This board used Activision software which Sue had spent some time learning; however only one other board in the school was a Panasonic board and the others were Smartboards and used Notebook 10. This meant that the resources Sue had developed could not be shared with many others in the school unless they used the Panasonic board. Sue didn't mind the Activision software as it had a greater range of mathematics tools than other alternative software. She also commented on the way that using the board and associated software had changed the way she approached her lessons as she had much better ways to demonstrate and explain mathematical concepts.

The board was used primarily in a teacher directed fashion, with students taking turns to do small tasks such as dragging terms and definitions onto a diagram of a parabola. Students in the lower achieving group were very keen to participate and to have a turn. In contrast, students in the accelerated group did not call out for turns, but were happy to do so when asked. Sue did not use the board for group work, and students still worked in exercise books, with lessons often taken from the text book and put into a more interactive form for use on the board with Activision software. Sue often used the board as a projector, sometimes displaying Word documents of worksheets as a way of getting students settled.

Sue found that the lower level group were not particularly engaged with the board until it came time for students to have a turn, at which point there was quite a lot of excitement, and turn taking strategies were used by Sue to ensure fair and appropriate turn taking took place. The accelerated group appeared more engaged with the lesson than the board, but Sue felt this may be because when the board was new they had been able to come out the front and have a play with it for a while, and therefore the novelty had worn off, but also that these students were more focused on learning the subject content. Sue also commented that behaviour management issues were minimal when the board was used as students generally focused on it during the lesson.

Sue primarily taught herself the software, even though she had attended formal department professional development session, she noted that the department had changed from favouring Activision to Notebook software. Sue commented that she learns a lot from the students who often show her different or easier ways of doing something on the board. Sue was not aware, however, of any specific academic improvement in her students.

\section{Hannah}

Hannah taught a Kindergarten-Year 1 composite class (age range 5-7) at a rural primary school. At the commencement of the study she was a student teacher on a 10 week internship late in her fourth and final year of study. Subsequently she was employed as a casual teacher teaching the same class and continued her involvement in the study in this capacity. Prior to the study she had used an IWB very briefly during her teacher training but had not used one in her teaching.

Hannah's initial experiments with the IWB often involved reasonably scripted lessons using downloaded Smart Notebook resources. She initially encountered difficulty in maintaining the interest and engagement of all students due to the difficulty of 
managing turn taking with such a young class. Later her practice evolved to use a wider range of resources, including those developed by herself, and a wider range of strategies, and to better structure both on board and off board tasks to ensure greater engagement of a larger proportion of the students.

Some of Hannah's most successful IWB strategies included: an activity where a student typed a story on the board in advance of others taking turns to correct spelling and punctuation errors they identified; the showing of a You Tube video of the song 'Incy Wincy Spider' as part of an exercise in understanding narrative in songs; and an activity where students together designed a wanted poster on the IWB before going to the computer lab and creating their own. Overall Hannah felt that the most important benefit of the IWB for students of this age was the ability to supplement text material with pictures to scaffold the weaker readers through activities focusing on certain reading and writing concepts.

\section{Discussion of common themes and overall findings}

\section{General themes}

One of the key findings of this exploration was the diversity in IWB use by teachers. Consistent with others studies, such as Shenton and Pagett (2007) and Way et al. (2009), across all of our cases there was far more diversity than consistency. The frequency of use of the IWB varied greatly between teachers. Classroom management and motivational use of the boards also varied from teacher to teacher, as did the actual role that the board played in the teaching and learning program. Although the use of the IWBs showed considerable diversity, there was a commonality in terms of teacher response to the technology. All of those who were part of this study reported a considerable enthusiasm for the IWB as well as considerable operational confidence.

In terms of frequency of use, the year 6 teacher used it as part of almost every teaching session ('I don't tend to go up to the lab a lot now, and have everybody on different computers, I tend to use the smart board more often' - Sally, 6/09). The K1 teacher used it at least for part of each day. The secondary maths and English teachers used it for most lessons. The secondary HSIE teacher used it most lessons but rarely for any purpose other than as a way of projecting presentations and videos. The secondary science teacher used the IWB frequently considering it to be vitally important. It saved preparation time, offered class control value and flexible teaching:

I don't spend lots of time writing down experiments, writing out anything on the board anymore, ... if I haven't pre-typed something, the typing is actually very quick anyway and I can talk to the kids while I'm typing it and I haven't got my back to them either. (Amanda, 9/09)

While IWBs are being used in quite diverse ways, one commonality is their availability. In common with all teaching technologies unless the technology is in the classroom and operational, teachers are unlikely to use it (Lee \& Winzenried, 2009).

Although, consistent with earlier studies (Beeland, 2001; Morgan, 2008), the motivational value of the IWB was a recurring theme, there was considerable diversity in terms of how that motivation was provided or controlled. Primary sector teachers sometimes used their boards as a reward, for example, by allowing individuals to play on the IWB after they had finished their work, rewarding the whole class with an IWB 
activity once other work was complete, or just using it to display videos or play music while students were working:

the junior classes you can sort of have it going almost every lesson, there's something there to do. (Sue, 8/09)

we still went onto YouTube and pulled up songs and that was a lot of fun stuff for them. When we were doing art, I'd often pull up music for them to play which they enjoyed listening to while they were doing it and they had some favourites. (Hannah, $12 / 09)$

This use of the board was not reflected among the secondary teachers where usage was more specifically content directed:

it's a more difficult novel, but visiting it via PowerPoint will be like seeing a little film on it, and I think that would, in a sense, extend everybody to some degree. (Grace, $8 / 09)$

The majority of use of the IWB for these teachers was as a whole class either with the teacher operating the board, or with students taking turns to operate it while the teacher used traditional 'chalk and talk' style strategies to draw the attention of the students to the key concepts or ideas involved in the activity. In some cases the activity on the IWB replicated an activity being carried out by the remaining students, either on laptops or on paper, while in other cases the activity provided a focus for a whole class oral activity, which might be followed up by a written activity afterwards. Zevenbergen and Lerman (2008) suggest that teacher directed approaches using IWBs can result in shallow learning, but there is no evidence from this study to suggest that this was the case. Sweeney (2010) and Hodge and Anderson (2007) both described studies in which teachers initially used their IWBs in a teacher-directed way but gradually evolved their practices so that students were more active participants in lessons. Consistent with this, there was some evidence that such an evolution had begun at least for the year 6 primary teacher. Time will tell whether this occurs with the other five teachers in the study.

Classroom management issues tended to display the same levels of diversity as did teacher use of the technology. However, one significant commonality was the effect that use of the IWB had on student behaviour:

you don't have too many behaviour problems when the interactive whiteboard is up and running. (Sue, 08/09)

Most teachers in our study had done some formal training with IWBs. Additionally, all of them had devoted considerable amounts of their own time to this. There was evidence that in some cases they went to additional trouble in preparing their IWB lessons because they were being observed as part of our project. A number of them commented that some of their peers were less enthusiastic about adopting technologies, and that facilitating widespread adoption was challenging. This seemed to be more the case in the secondary school than the primary school.

A wide range of software and associated resources were used by the teachers in this study. Smart Notebook resources, either downloaded or provided with the IWB were probably the most common used by the two primary teachers - including those for presentation purposes as well as those with interactive elements. Only a couple of the teachers mentioned that they had made their own Smart Notebook resources. PowerPoint 
presentations either developed by the teacher or by the students were used regularly by some secondary teachers.

we're all PowerPoint mad - building up our resources, so that we've each made a PowerPoint on the novel - the PowerPoint on poetry - you know, the PowerPoint on drama - that we can share. (Grace, 8/09)

A number of teachers gave examples of the use of the IWB as an interface to Internet based resources on current events. This included access to online newspapers and public news web sites, You Tube videos and specialised news sites for students such as Behind the News. In some cases these online current affairs resources were supplemented with tools like Google Maps or Google Street View which allowed the students to position the events relative to themselves or visualise the places where events were occurring:

we love using Google Maps, we do that a lot. (Sally, 9/09)

Interestingly none of the six teachers mentioned that they used the Learning Federation learning objects (a large learning object repository funded by the Australian government and available to all schools in Australia; The Le@rning Federation, undated). It is possible that resources that can be located and downloaded with simple web searches are more likely to be used by teachers than those hidden behind password protected sites.

\section{Attitudes to technology}

Teachers in this study were very positive about the introduction of IWBs and this seems to be common to each of our teachers. This is consistent with some earlier studies (e.g. Lee \& Boyle, 2003) which found immediately positive teacher reactions to the use of an IWB, but contrasts with other studies such as Glover and Miller (2001) which found substantial variability in teacher's reactions to the technology, and Gatlin (2004) which reported initial resistance from some teachers. The advantages of the technology seem to be appreciated quickly and the potential for teaching viewed as considerable. Both of these issues were common themes throughout the study. While some disadvantages were voiced occasionally, these were usually placed in close context with an enthusiasm for the technology and a positive view of its potential for improvement in both teaching and effective learning. Positives included the 'large screen' ("it is absolutely fantastic to have a big screen to show the film", Grace 9/09), the immediacy, and the attractiveness of presentations using the technology. Teachers felt positive, even invigorated, by the IWB.

This high degree of optimism did not seem to lessen with time. During the whole course of the investigation, each of those taking part continued to express significant enthusiasm; particularly in relationship to the value of the boards in engaging their students. Quite importantly, there was no noticeable difference in acceptance due to technical experience or IWB experience in particular. Novice or more technically experienced, each respondent appeared equally accommodating.

\section{Preparation}

The introduction of the IWB was seen as directly related to a change in teacher preparation. In terms of preparation activity, the IWB caused teachers to search more intensively for "new" resources (those suitable for use with the new technology). 
Further, this tended to introduce a greater element of excitement and general enthusiasm for classroom content. The search for new content was seen as initiating a revitalised approach with new ideas and resources.

Teachers in general indicated that the board required increased preparation time for lessons but that the time required gradually reduced over time: "I've noticed now that my prep times seem to be coming down" (Hannah, 12/09).

This was perhaps more pronounced though in the secondary sector, where there was an appreciation that new lesson materials could be reused as well as being used more flexibly.

it just makes it easier ... I actually don't spend a lot of time preparing my lessons, and I think a lot of teachers once they've been teaching for a few years can probably say the same sort of thing, and being head teacher there's always something that comes up and just busy doing something and it's maybe 5 minutes before the lesson, oh I haven't worked out what I'm doing yet, just quickly jump on the Internet and oh yeah this is great, good, lesson sorted ... (Amanda, 9/09).

The net result was a reduction (or perceived reduction) in preparation time overall for some teachers. This was further affected by a possible rise in peer support as teachers shared the new resources that they found with their colleagues. This also illustrates, as suggested by Bennett and Lockyer (2008), the way in which the IWB can be an accessible technology for teachers which allows them to gradually migrate their existing resources and pedagogical approaches rather than requiring them to completely rethink how they teach.

Teachers regularly mentioned the value of being able to bring up material from earlier lessons as a way of revising work or continuing an earlier discussion. Generally the saved materials consisted of notes created from class discussions using the Smart Notebook software or alternatively interactive Smart Notebook resources which had been partially completed as a class activity. The ability to "reuse" material was frequently cited as a key affordance of the technology:

it just means that if I've gone to the effort of finding something, then that reference to that can actually go into the programs so other teachers can look up those things and use them. (Amanda, 10/09)

Reuse of resources was seen as one of the factors contributing to an anticipated future reduction in teacher preparation time that was cited by a number of the participants in this study:

it will be quicker in the future because I'm not going to be reinventing all the time. (Grace, 10/09)

\section{Teaching}

There were numerous examples in the interviews of teachers undertaking high levels of reflection on their use of the IWB and on their teaching practice in general

I'm going to have to learn that in preparing .... You know, I prepared that lesson .... So I think the lesson that I'm getting out of it is I've got to cut the content that I throw up there. I do talk a lot. (Sue, 8/09) 
... probably needed something three-quarters of the way through that was a bit more appealing to them to pull them back in. (Sue, 8/09)

They consistently reported a more critical approach to what they were doing and why they were doing it. This finding is important given Mohon's (2008) suggestion that pedagogical change through the use of an IWB will be limited by the teacher's readiness to pursue new ideas. The fact that all of the teachers who participated in this study illustrated a readiness to evolve their IWB pedagogical strategies through reflection on practice supports the findings of Sweeney (2010) and Hodge and Anderson (2007) who described positive improvements in pedagogical approaches over time.

\section{Professional development}

More sharing of resources was also mentioned alongside a new preparedness among colleagues to help with technical issues, provide ideas for board use, and generally offer additional "tips" and training. Although formal professional training was seen as a major need by most of those participating, there was also a feeling of "we are not alone", as their peers offered considerable support. With the majority being self or peer taught, professional training was seen as likely to offer future development, but a lack of such training had not prevented each of them from using the technology:

I didn't mind the things that went wrong because they were things that you could really learn from and that was great, that was good. (Grace, 8/09)

One further aspect was that of learning from the students themselves. This was generally seen in a very positive light:

... you build up a rapport with the kids that if I don't know, I'll admit it, and the kids will say, no you do this, and I think the kids love being able to show me what they know on me so I'm not really worried about me being behind, well I am a bit, I'd like to know more, but at least I know that the kids will show me and as soon as the kids get the laptops, I'll learn a lot quicker. (Grace, 8/09)

they've shown me some really good stuff. Very relevant stuff. Some irrelevant stuff too, by the way. (James $11 / 11$ )

The positive way in which teachers viewed this student support was significant:
he's the one whose inspired me to make ... our next unit in year ten, that they each make a movie, which really phases me but he said, you don't know how easy it is, I will help you, you'll be right, I have all the gear and isn't that wonderful? (Grace 4/09)
they're way above me in there, I've had kids, a couple of kids who have the skills, have made movies instead of PowerPoints and some of them have done phenomenal jobs and they love showing you and, you know it's great to learn from them, they always teach you? (James 12/08)

Formal PD was not always seen as successful, the general feeling being that, consistent with the suggestions of Miller and Glover (2007) and of Shenton and Pagott (2007), peer support in conjunction with personal trial and error were seen as the more effective means of learning how to use the technology:

one problem that I had is that I did some training Term 3 last year, so it is quite some time ago now, in using the Activestudio software and then the contract changed or 
whatever it was and it's different software now and I actually haven't really had the chance or taken the time to figure out how to use the software that I have. (Amanda, 9/09)

\section{Conclusion}

Two conclusions may be drawn from our findings. Firstly, interactive whiteboards did not appear to decrease the opportunities for a richness and diversity in teaching and learning in the classrooms observed in this study. They appeared to provide a tool as flexible, responsive and individual as the teachers and their learners. Secondly, IWB technology appeared to offer teachers a considerable range of affordances that other technologies may not. Access to a wider range of highly motivating and contemporary resources and a clear increase in the levels of student engagement with their learning were key consequences of the activities afforded by the IWBs for all teachers.

An important outcome stemming from these findings is that professional development to extend the use of this technology needs to reflect the diversity of its use. Formal, standardised workshops are unlikely to be as valuable as peer discussion which promotes reflective learning supplemented by just in time support to allow quick resolution of technology problems. Clearly, though, regardless of the training or professional learning opportunities provided, the evidence suggests that IWBs will be a technology that is readily adopted by almost all teachers and one that, rather than being locked away in a dusty storeroom when the initial gloss wears off, will continue to be used and will result in incremental but sustained developments in teaching practice.

\section{Acknowledgments}

We would especially thank the staffs of participating schools and their administrations. Without their unstinting support and co-operation, a study such as the present one would be impossible. The authors would also like to acknowledge the contribution of Lauren Carlson to the coding of transcribed interviews.

\section{References}

Armstrong, V., Barnes, S., Sutherland, R., Curran, S., Mills, S. \& Thompson, I. (2005). Collaborative research methodology for investigating teaching and learning: The use of interactive whiteboard technology. Educational Review, 57(4), 457-470.

Beauchamp, G. (2004). Teacher use of the interactive whiteboard in primary schools: Towards an effective transition framework. Technology, Pedagogy and Education, 13(3), 327-348.

Beeland, W. (2001). Student engagement, visual learning and technology: Can interactive whiteboards help? Paper presented at Annual Conference of the Association of Information Technology for Teaching Education, Trinity College, Dublin. [viewed 17 May 2010]. http: / / chiron.valdosta.edu/are/Artmanscrpt/vol1no1/beeland_am.pdf

Bennett, S. \& Lockyer, L. (2008). A study of teachers' integration of interactive whiteboards into four Australian primary school classrooms. Learning, Media and Technology, 33(4), 289-300.

BrainPOP (undated). Animated Educational Site for Kids - Science, Social Studies, English, Math, Arts \& Music, Health, and Technology. http:/ / www.brainpop.com/ 
Chuang, H.-M., Shen, C.-C. \& Wang, L.-C. (2008). Using an interactive response system in conjunction with interactive whiteboards technology to enhance learning. In Proceedings Fourth International Conference on Natural Computation, Jinan, China, vol. 2, pp.657-661.

Cuban, L. (2001). Oversold and underused: Computers in the classroom. Cambridge, Mass.: Harvard University Press.

Cutrim Schmid, E. (2007). Enhancing performance knowledge and self-esteem in classroom language learning: The potential of the ACTIV ote component of interactive whiteboard technology. System, 35(2), 119-133.

Cutrim Schmid, E. (2008). Potential pedagogical benefits and drawbacks of multimedia use in the English language classroom equipped with interactive whiteboard technology. Computers $\mathcal{E}$ Education, 51(4), 1553-1568.

Gatlin, M. (2004). Interactive whiteboard system creates 'active classrooms' for rural Georgia school system. T H E Journal (Technological Horizons In Education), 31(6), 50. http: / / thejournal.com/articles / 2004/01/01/interactive-whiteboard-system-creates-activeclassrooms-for-rural-georgia-school-system.aspx

Glover, D. \& Miller, D. (2001). Running with technology: The pedagogic impact of the large-scale introduction of interactive whiteboards in one secondary school. Technology, Pedagogy and Education, 10(3), 257-276. [verified 14 Jun 2010]

http: / / pdfserve.informaworld.com/570790_739086631.pdf

Glover, D. \& Miller, D. (2002). The introduction of interactive whiteboards into schools in the United Kingdom: Leaders, led and the management of pedagogic and technological change. International Electronic Journal for Leadership in Learning, 6(24). [viewed 17 May 2010]. http:/ / www.ucalgary.ca/iejll/glover_miller

Glover, D., Miller, D., Averis, D. \& Door, V. (2007). The evolution of an effective pedagogy for teachers using the interactive whiteboard in mathematics and modern languages: an empirical analysis from the secondary sector. Learning, Media and Technology, 32(1), 5-20.

Gray, C., Pilkington, R., Hagger-Vaughan, L. \& Tomkins, S. (2007). Integrating ICT into classroom practice in modern foreign language teaching in England: Making room for teachers' voices. European Journal of Teacher Education, 30(4), 407-429.

Haldane, M. (2007). Interactivity and the digital whiteboard: Weaving the fabric of learning. Learning, Media and Technology, 32(3), 257-270.

Hall, I. \& Higgins, S. (2005). Primary school students' perceptions of interactive whiteboards. Journal of Computer Assisted Learning, 21(2), 102-117.

Hammond, M., Crosson, S., Fragkouli, E., Ingram, J., Johnston-Wilder, P., Johnston-Wilder, S., et al. (2009). Why do some student teachers make very good use of ICT? An exploratory case study. Technology, Pedagogy and Education, 18(1), 59-73.

Hedberg, J. \& Freebody, K. (2007). Towards a disruptive pedagogy: Classroom practices that combine interactive whiteboards with TLF digital content. [viewed 19 Mar 2008, verified 14 Jun 2010] http: / / www.thelearningfederation.edu.au / verve/_resources/towards_a_ disruptive_pedagogy.pdf

Higgins, S. (2003). Does ICT improve learning and teaching in schools? [viewed 30 Jan 2006, verified 14 Jun 2010]. http:/ / www.bera.ac.uk/ files/reviews/ict-pur-mb-r-f-p-1aug03.pdf

Hodge, S., \& Anderson, B. (2007). Teaching and learning with an interactive whiteboard: A teacher's journey. Learning, Media, \& Technology, 32(3), 271-282.

Holmes, K. (2009). Planning to teach with digital tools: Introducing the interactive whiteboard to pre-service secondary mathematics teachers. Australasian Journal of Educational Technology, 25(3), 351-365. http:/ / www.ascilite.org.au/ajet/ajet25/holmes.html 
Jewitt, C., Moss, G. \& Cardini, A. (2007). Pace, interactivity and multimodality in teachers' design of texts for interactive whiteboards in the secondary school classroom. Learning, Media and Technology, 32(3), 303-317.

Jones, A. \& Vincent, J. (2006). Introducing interactive whiteboards into school practice: One school's model of teachers mentoring colleagues. In Australian Association for Research in Education Conference, Adelaide. [viewed 17 May 2010] http://www.aare.edu.au/06pap/jon06333.pdf

Kennewell, S. (2006). Reflections on the interactive whiteboard phenomenon: a synthesis of research from the UK. In Australian Association for Research in Education Conference, Adelaide. [viewed 17 May 2010] http: / / www.aare.edu.au/06pap/ken06138.pdf

Kent, P. (2004). e-Teaching: The elusive promise. In R. Ferdig et al. (Eds.), Proceedings of Society for Information Technology \& Teacher Education International Conference 2004 (pp. 520-522). Chesapeake, VA: AACE.

The Le@rning Federation (undated). http: / / www.thelearningfederation.edu.au /

Lee, M. \& Boyle, M. (2003). The educational effects and implications of the interactive whiteboard strategy of Richardson Primary School: A brief review. [viewed 30 Jan 2006, verified 14 Jun 2010] http:/ / www.richardsonps.act.edu.au /_data/assets / pdf_file/0020/ 83117 /RichardsonReview_Grey.pdf

Lee, M. \& Winzenried, A. (2009). The use of instructional technology in schools. Melbourne: ACER Press.

Lewin, C., Scrimshaw, P., Somekh, B. \& Haldane, M. (2009). The impact of formal and informal professional development opportunities on primary teachers' adoption of interactive whiteboards. Technology, Pedagogy and Education, 18(2), 173-185.

Lewin, C., Somekh, B. \& Steadman, S. (2008). Embedding interactive whiteboards in teaching and learning: The process of change in pedagogic practice. Education and Information Technologies, 13(4), 291-303.

Miles, M. \& Huberman, A. (1994). Qualitative data analysis: An expanded sourcebook. Thousand Oaks, CA: SAGE publications, Inc.

McCormick, D. (2007, May). Interactive whiteboards in the classroom: A primary teacher's perspective. Pen-based learning technologies. Paper presented at the First International Workshop on Pen-Based Learning Technologies (PLT 2007), Catania, Italy, May 24-25. IEEE Computer Society.

McKendrick, J. H. \& Bowden, A. (1999). Something for everyone? An evaluation of the use of audio-visual resources in geographical learning in the UK. Journal of Geography in Higher Education, 23(1), 9-20.

Miller, D. \& Glover, D. (2007). Into the unknown: The professional development induction experience of secondary mathematics teachers using interactive whiteboard technology. Learning, Media and Technology, 32(3), 319-331.

Mohon, E. (2008). SMART moves? A case study of one teacher's pedagogical change through use of the interactive whiteboard. Learning, Media and Technology, 33(4), 301-312.

Morgan, G. L. (2008). Improving student engagement: Use of the interactive whiteboard as an instructional tool to improve engagement and behavior in the junior high school classroom. (Unpublished dissertation). Liberty University, Virginia. [viewed 11 April 2010] http: / / digitalcommons.liberty.edu / cgi/ viewcontent.cgi?article=1140\&context=doctoral

Reedy, G. (2008). PowerPoint, interactive whiteboards, and the visual culture of technology in schools. Technology, Pedagogy and Education, 17(2), 143-162. 
Schuck, S. \& Kearney, M. (2007). Exploring pedagogy with interactive whiteboards: A case study of six schools. Sydney: University of Technology Sydney. [viewed 16 May 2007, verified 14 Jun 2010; 8.5 MB] http:/ / www.ed-dev.uts.edu.au/teachered/research/iwbproject/pdfs/iwbreportweb.pdf

Shenton, A. \& Pagett, L. (2007). From 'bored' to screen: The use of the interactive whiteboard for literacy in six primary classrooms in England. Literacy, 41(3),129-136.

Smith, B. K. \& Blankinship, E. (2000). Justifying imagery: Multimedia support for learning through exploration. IBM Systems Journal, 39(3/4), 749-768.

Smith, F., Hardman, F. \& Higgins, S. (2006). The impact of interactive whiteboards on teacher pupil interaction in the National Literacy and Numeracy Strategies. British Educational Research Journal, 32(3), 443-457.

Smith, H. (2003). Interactive whiteboard evaluation. [viewed 24 Jan 2006; not found 14 Jun 2010] http: / / www.kented.org.uk/ngfl/ict/IWB/index.htm

Somekh, B. (2004). Taking the sociological imagination to school: An analysis of the (lack of) impact of information and communication technologies on education systems. Technology, Pedagogy and Education, 13(2), 163-179.

Stake, R. (1995). The art of case study research. London: Sage Publications, Inc.

Sweeney, T. (2010). Transforming pedagogy through interactive whiteboards: Using activity theory to understand tensions in practice. Australian Educational Computing, 24(2), 28-34.

Way, J., Lilley, E., Ruster, C., Johnco, S., Mauric, L. \& Ochs, L. (2009). Symposium: Interactive whiteboards and pedagogy in primary classrooms. In Proceedings Australian Association for Research in Education Conference. [viewed 12 April 2010] http: / / www.aare.edu.au/09pap/ way091149.pdf

Wishart, J. \& Blease, D. (1999). Theories underlying perceived changes in teaching and learning after installing a computer network in a secondary school. British Journal of Educational Technology, 30(1), 25-42.

Wood, R. \& Ashfield, J. (2007). The use of the interactive whiteboard for creative teaching and learning in literacy and mathematics: A case study. British Journal of Educational Technology, 39(1), 84-96.

Zevenbergen, R. \& Lerman, S. (2008). Learning environments using interactive whiteboards: New learning spaces or reproduction of old technologies? Mathematics Education Research Journal, 20(1), 108-126. http:/ / www.merga.net.au/documents/MERJ_20_1_Zevenbergen.pdf

Dr Arthur Winzenried, Lecturer, School of Information Studies

Charles Sturt University

Boorooma Street, Wagga Wagga NSW 2678, Australia

Email: awinzenried@csu.edu.au

Dr Barney Dalgarno, Associate Professor in Education, School of Education

Charles Sturt University

Boorooma Street, Wagga Wagga NSW 2678, Australia

Email: bdalgarno@csu.edu.au

Jacquie Tinkler, Lecturer - Curriculum Studies, Faculty of Education

Charles Sturt University

Boorooma Street, Wagga Wagga NSW 2678 Australia

Email: jtinkler@csu.edu.au 